\title{
Impact of Fast Automated Tracking of Construction Components on Labor Productivity
}

\author{
David Grau ${ }^{1}$, Carlos H. Caldas², Carl T. Haas ${ }^{3}$, Paul M. Goodrum4, and Jie Gong 5
}

${ }_{1}^{1}$ Assistant Professor, Department of Civil, Construction, and Environmental Engineering, The University of Alabama, Box 870205, Tuscaloosa, AL 35487-0205, Tel. (205) 348-6167, FAX (205) 348-0783, dgrau@eng.ua.edu

2 Assistant Professor, Department of Civil, Architectural, and Environmental Engineering, The University of Texas at Austin, 1 University Station C1752, Austin, TX 78712-0273, Tel. (512) 471-6014, FAX (512) 4713191,caldas@mail.utexas.edu

${ }^{3}$ Professor, Department of Civil Engineering, University of Waterloo, 200 University Avenue West, Waterloo, Ontario, N2L 3G1, Canada, Tel. +1 (519) 888-4567, FAX +1 (519) 888-4300, chaas@civmail.uwaterloo.ca ${ }^{4}$ Associate Professor, Department of Civil Engineering, 151C Raymond Building, University of Kentucky, Lexington, KY 40506-0281, Tel. (859) 257-5416, FAX (859) 257-4404, pgoodrum@engr.uky.edu

${ }_{5}$ Ph.D. Candidate, Department of Civil, Architectural, and Environmental Engineering, The University of Texas at Austin, 1 University Station C1752, Austin, TX 78712-0273, Tel. (512) 471-8417, FAX (512) 4713191,jie.gong@mail.utexas.edu

\section{Abstract}

Even though the fundamental importance of construction components in any given project, industry practices still solely rely on the human ability to individually control thousands of these components on the field. This lack of automation frequently results in critical errors that negatively affect project cost and schedule. Recently, though, the undemonstrated notion that materials tracking processes can highly benefit from the implementation of information technologies has been gaining wide industry acceptance. This paper presents the results of a massive study on a large industrial site that aimed at quantifying the impact associated with automating materials tracking processes on craft labor performance. For this purpose, field records from manual and automated tracking processes were collected during the trial. Then, the influence of the automated tracking process on construction performance was determined by considering the manual approach as the baseline for comparison. The results indicate that information technologies can significantly enhance craft labor productivity.

\section{Motivation}

Advances in technology have many benefits and among the most often cited are improved quality and productivity. The evolution within the communications industry can be seen as one example of how innovation has been embraced and leveraged on a continuing basis. Arguably, the construction industry lags in this regard and underutilizes advances in technology. However, the opportunity to improve construction productivity exists, and there is evidence that sectors of the construction industry have experienced long term productivity growth as a result.

Economic research has shown that technology tends to have a greater impact on labor productivity versus factor productivity measures. For example, investment in new equipment technology may improve an organization's labor productivity, but their factor productivity may actually decline if the relative increase in the cost of the equipment outweighs the relative savings in labor costs and gains in output. While there is evidence that improvements in equipment and material technology have a positive impact on construction productivity, the impact of information technology has remained largely undocumented.

Industry practitioners have recently identified site materials tracking as a process highly susceptible of being improved by new information technologies (Vorster and Lucko 2002). According to a wide survey among a large number of practitioners, new technology devices offer site materials management the greatest potential for improvement and the greatest potential for positive economic impact on engineering 
construction projects. Moreover, this synergistic integration also opens the possibility of doing more work with fewer people and reducing the number of safety incidents.

Even though the opportunity to advance material handling practices exists throughout the industry, industrial project sites offer the greatest potential for improvement. On these sites, the challenges that their materials handling practices need to satisfy steadily increase over time. As project demands and regulations increase over the years so does the number of engineered components. Actually, materials managers need to control thousands of unique components over several years and throughout areas covering tens or hundreds of acres. During their storage, a large percentage of components is frequently moved making their proper control unattainable and negatively impacting project performance. Projects with remote-site locations are a prominent example. That a component required in the critical path is lost and needs to be re-ordered to a distant manufacturer virtually guarantees that the component will not be available for installation when required. This kind of materials management oversight increases total installed costs and can eventually delay a whole project.

This imbalance between the magnitude of the tracking effort and the manual approach to it is reflected in the historically low efficiency of manual tracking processes. It has been consistently observed that workers waste up to a third of their working time in search of the items that they need or waiting idle for their availability while others are searching for them (Rojas and Aramvareekul 2003; Caldas et al. 2006). Anecdotal data also show that the amount of time needed to search for a particular component can randomly range from a few minutes to several hours (Grau 2008). In addition, an effective materials management system can not only prevent loosing components but also minimize the surplus of re-ordered pieces at the end of the project (CII 1999).

That there is not factual data demonstrating the potential benefits associated with the implementation of advanced tracking technologies seems to reasonably explain the lack of their actual adoption by the construction industry. Even if the industry assumes this advantage, the reality is that how these technologies actually impact craft labor performance and installation processes has not been previously studied. Overall, the questionable offset of this standing barrier is preventing the deployment of technology-supported tracking processes by the capital investment industry.

\section{Background}

A variety of technology-based approaches have been recently proposed to improve the monitoring of construction materials. These research efforts have primarily used Radio Frequency Identification (RFID), Global Positioning System (GPS), and several other sensing technologies to simplify and automate the tasks of identifying and locating construction components. Identification-based efforts were found to increase supply chain visibility when RFID was combined with barcodes (Navon and Berkovich 2006). This RFID technology also facilitated both the tracking of construction tools and the storing of their operational data in building environments (Goodrum at al. 2006). Other research has analyzed the potential of combining RFID technology with localization algorithms to locate construction components (Song et al. 2006; Grau and Caldas 2008).

The GPS positioning technology has also been placed on top of hard hats to infer labor activities from workers' positions (Sacks et al. 2003). GPS was also implemented on an industrial project to record the present time positions of pipe spools and was found to substantially reduce locating times (Caldas et al. 2006).

In spite of these successful applications of sensing technologies, the impact of automated tracking methods on project performance remains undetermined. Assessing and quantifying the benefits from automating site tracking practices can drive their actual implementation on the job sites.

\section{Research Questions}

This study is defined by two research questions:

1. Materials handling practices can be automated to effectively monitoring the status of a large number of components under challenging type of conditions, such as those of construction job sites.

2. The automation of materials tracking practices has a positive economic impact on project performance. In order to satisfactory answer both questions; a research approach based on a trial run that compared the performances between manual and automated materials tracking processes was developed. 


\section{The Project Site}

The purpose of this study is to estimate the impact of materials tracking technologies on craft labor productivity, labor efficiency, and percentage of missing components. Using a manual tracking process as a baseline, a massive trial run determined the productivity impact associated with the automated monitoring of steel components in a $\$ 750$ million power plant project site ruled by open shop and direct hire policies. The project site had two almost identical boiler-support steel structures. Both steel structures were erected in equal sequences of installation with a time gap that oscillated between one and two weeks only.

In terms of materials, the project site was divided into two nearby areas: the lay down yard and the staging area. The lay down yard extended over an area of 25 acres and stored the structural steel elements from the moment they were received until the moment they were retrieved for their installation at the staging area. At the staging area, the components were prepared for their erection around the boiler structures in a very limited amount of space.

\section{The Materials Tracking Process}

Structural steel components were stored at the lay down yard directly from the trucks that delivered them. Adjacent grids partitioned the lay down yard area for location purposes. Each grid extended over an area of $30 \mathrm{x} 15 \mathrm{~m} 2$ and could be identified by a coded metallic post at its center. Each component was identified by its unique piece mark, which was engraved in a tiny steel plate that had been previously welded to the component. In order to make the identification of a component more evident to craft workers, its corresponding piece mark was written on the component at its delivery. Then, craft workers manually recorded the piece marks of the components and their corresponding grid locations for inventory purposes. Later, this information was typed into a project management system. If a steel element was moved to a different grid, crews were expected to record the new grid location data with the aim of updating it into the management system.

Based on the stored data, foremen submitted a materials withdrawal request (MWR) with a list of the components requested for installation. In order to minimize the presence of components in the spaceconstrained staging area, MWRs were submitted the same day or the day before the installation of their listed components. Based on the requested components and their grid-recorded locations, craft workers searched for them. If a component could not be located, workers utilized additional data from its detailed drawings to identify it. Once found, craft workers tagged the component with a colored tape. Different tape colors were assigned to different boiler installation sequences. Hence, tagging allowed erection crews to immediately identify and load the components to be retrieved onto flat bed trucks. That the hourly cost of craft workers was half of the hourly cost of erection crews and that this later crews operated costly pieces of equipment explains why management preferred craft workers for the time-consuming search of lay down yard components. Once beyond the lay down yard, components were not tracked.

At the staging area, components were stored nearby their rigging position in order to minimize their movement. Once lifted and placed into position, other crews bolted, plumbed, aligned, painted, and inspected each steel component.

\section{Opportunities for Positively Affecting Labor Performance}

Even though the materials management system was the most sophisticated the authors have observed over the years, advanced technology devices opened the door for its improvement. The opportunities for improvement are summarized below:

- Reduction of locating times at the lay down yard. The manual tracking process prevented efficient and reliable searches. Frequently, components were in a different grid than those indicated by records. In these cases, workers would need to spend unnecessary amounts of time searching for the components that they could not find. Even in the instances of correctly inventoried components, the $450 \mathrm{~m}^{2}$ grid-size made searches inefficient.

- Percentage of not-immediately-found components. Craft workers had to frequently re-search for components that had not been found using the available information. These random searches required four or five workers on average and could last an entire day, further extending location times.

- Reliable support for installation processes. The inability to immediately supply the staging area with steel components for their installation decreased erection productivity. 
- Monitoring of components in the installation area. The status of components pending for installation at the staging area was always unknown. This lack of information further jeopardized the installation process by creating confusion among erection crews. Thus, erection crews were observed to spent considerable amounts of time figuring out the whereabouts of the components planned for installation.

\section{Automated Materials Tracking Technology}

The automated materials tracking process is based on the combination of localization algorithms, and GPS and RFID technologies. Initially, RFID tags were attached to the components to be tracked. Then, the positioning and identification sensors were hung together from a piece of roving equipment. While roving throughout the jobsite, the GPS receiver determined its own position and the RFID reader identified the signals from the emitting components around this position. Then, localization algorithms estimated the location of the tagged components by processing the time series of location and identification data. On average, the resulting accuracy of these estimated locations was better than ten feet. Maps representing the position of the estimated location of the components could be generated to support field searches. Grau and Caldas (2009) provide a comprehensive description of this automated tracking technology.

\section{Trial Design}

The trial design was based on the existence of two identical boiler (hereafter named A and B) units with equivalent sequences of installation. The authors utilized these matching conditions coupled with the fact that each boiler had its independent foreman and crews to the advantage of this study. These ideal conditions enabled the direct comparison of unbiased productivity measures. While 400 Boiler B components were tagged and abided by the automated tracking process, their equivalent Boiler $\mathrm{A}$ components abided by the manual tracking process. Then, site-wide records from both sets of components were collected in tandem from their storage at the lay down yard until the moment they were lifted for installation. Both sets of collected records were used to determine the impact of the automated tracking process on project performance.

On the lay down yard, the authors collected the amount of craft worker time to inventory, locate, and flag the components. While MWRs for Boiler A were supported with a list of component identification and grid location information, MWRs for Boiler B components were supported with user-friendly maps representing the estimated locations of the required components. On the staging area, the contractor continuously collected engineering data, project controls data, and foreman delay surveys for each boiler unit. While the traditional tracking process did not monitor the components in the staging area, the authors provided the Boiler B foreman with an updated list of the components available for installation and an equivalent map with their corresponding positions.

\section{Performance Metrics}

A set of three metrics was defined to determine the impact of the automated tracking approach on project performance. These metrics were:

- Craft labor productivity at the lay down yard. The average time to inventory, locate, and flag the steel components.

- Percentage of components not-immediately-found at the lay down yard. The percentage of components that could not be located in an immediate manner with positioning and identification data and required extended search efforts.

- Steel erection productivity. The weight of erected components per work-hour -inclusive of the hours required for unloading, storing, identifying, locating, and erecting the steel at the staging area. The work hours required for the activities beyond the moment the materials had been lifted - such as bolting, plumbing, torquing, painting, or inspecting - were not considered due to their independence with respect to the materials management process. 


\section{Trial Results}

The trial evidenced a strong potential for improving project performance by automating site tracking processes. On the lay down yard, the automated tracking process minimized both the average labor time spent per component and the number of not-immediately-found components. In detail, the average labor time spent per steel component on the yard was reduced in a ratio of eight to one (See Table 1), a difference that proved to be statistically significant. This reduction was due to both the precise map estimated positions (versus the $450 \mathrm{~m} 2$ accuracy of the grids) and the minimized number of not-immediately-found components. Indeed, the percentage of components that required extended searches decreased from $9.53 \%$ to $0.54 \%$ (See Table 2). This is equivalent to say that for each twenty manually-tracked steel components that could not be immediately found by craft workers there was only one instance of automatically-tracked component. It was observed that craft workers were confident of the precise map locations to the extent that in the several instances of steel components that could not be rapidly found, craft workers directly reported the issue without extending their search to adjacent areas. However, craft workers had to inevitably perform these extended searches when components could not be found based on their corresponding grid locations.

Table 1 . Average craft labor time spent per lay down yard component

\begin{tabular}{cc} 
Tracking Method & Minutes \\
\hline Traditional & 36.80 \\
\hline Automated & 4.56 \\
\hline
\end{tabular}

Table 2. Percentage of components with extended search times

\begin{tabular}{cc} 
Tracking Method & $\begin{array}{c}\text { Percentage of } \\
\text { Not-Immediately-Found } \\
\text { Components }\end{array}$ \\
\hline Traditional & 9.52 \\
\hline Automated & 0.54
\end{tabular}

As a consequence of these differences, the average labor time per steel components was 36.80 minutes for the manual process and only 4.56 for the automated process (See Table 3). For the manual process, craft workers devoted 8.23 for inventorying, finding, and flagging each component, while only 2.93 minutes were required for the automated process. Complementarily, craft workers spent an average of 28.57 minutes per component in extended searches of non-immediately-found components for the manual process, while they only had to spend an average of 1.63 minutes for the automated process. These extended search times can be directly regarded as waste from a productivity perspective, being their values indicative of the gross potential for improvement of each type of tracking process.

Table 3. Average craft labor times per component

Traditional Tracking Method

\begin{tabular}{cc}
\hline Activity & Minutes \\
\hline Mark Component & 1.09 \\
\hline Record Grid Position & 0.41 \\
\hline Locate and Flag & 6.73 \\
\hline Extended Searches & 28.57 \\
\hline Average Time & 36.80 \\
\hline
\end{tabular}

Automated Tracking Method

\begin{tabular}{cc}
\hline Activity & Minutes \\
\hline Collect Data & 0.73 \\
\hline Locate and Flag & 2.20 \\
\hline Extended Searches & 1.63 \\
\hline Average Time & 4.56 \\
\hline
\end{tabular}


On the staging area, the erection productivity of tagged components incremented in $4.2 \%$ when compared to the components manually tracked (See Table 4). Since the contractor credited $50 \%$ of the installation right after the erection of steel elements - without considering the remaining activities of aligning, plumbing, bolting, and painting, this productivity increment is equivalent to a $2.1 \%$ increment in the overall installation productivity. However, the authors also analyzed the impact of the automated tracking process in the subset of components that were lighter than $500 \mathrm{Kg}$, such as small beams and hollow sections. As it could have been expected, the automation effect was higher on this more prone-to-loose subset of components, resulting in a $13.4 \%$ increment of erection efficiency.

Table 4. Erection productivity improvement

\begin{tabular}{cc}
\hline Components & Improved Productivity (\%) \\
\hline All & 4.2 \\
\hline Less than $500 \mathrm{Kg}$ & 13.4 \\
\hline
\end{tabular}

\section{Cost Effectiveness at the Project Site}

For a tracking technology to be feasible, it does not only need to result in increased productivity but also needs to be cost-effective. A benefit-to-cost analysis was performed to determine whether the benefits surpassed the upfront technology costs. Assuming that the 9,670 steel components had been tagged, almost a 2:1 benefit-to-cost ratio would have been achieved (See Table 5). In the pessimistic case that the fifteendollar tags could be re-used only once - these tags have a guaranteed battery life of six years, a close to 4:1 benefit-to-cost ratio would result - since benefits would double. Subsequent re-uses would further increase this highly positive benefit-to-cost ratio. In addition to these economic benefits, the installation schedule at the trial site could have been reduced in almost six days per boiler unit as a result of a more efficient erection process.

Table 5. Cost benefit of tagging all the steel components

\begin{tabular}{cc}
\hline Concept & Amount \\
\hline Lay Down Yard Savings & $\$ 103,920$ \\
\hline Staging Area Savings & $\$ 169,337$ \\
\hline Technology Costs & $(\$ 151,750)$ \\
\hline Benefits & $\$ 121,507$
\end{tabular}

There are two important remarks that the reader needs to be aware of. First, the contractor had implemented a very sophisticated materials management process, highly above the industry average in terms of efficiency. Over the years, the authors of this research have been able to observe that the degree of sophistication of site materials management practices varies widely. While some companies do not have any specified procedure to control site components, others have developed exhaustive site materials management processes based on project management information systems. Based on these observations it can be stated that the materials management process taken as the baseline for this study is much more sophisticated than an average industry process. Second, heavy steel items difficult to misplace or loose were the objective of the tracking process. Other objects, such as pipe spools or valves, can be more easily misplaced or lost. Overall, implementing a process for automatically tracking more prone-to-loose type of components on average type of projects can result in positive impacts far beyond those obtained in this study.

\section{Conclusions}

This study assessed and quantified the impact associated with the automation of site materials tracking processes on project performance. For this purpose, a massive field trial on a large industrial site was 
performed on the premises of tracking structural steel elements. A sophisticated traditional tracking process was the baseline for the improvements determined by this study.

The tracking approach surpassed the manual approach in every quantified aspect. The average labor time spent per tracked component was reduced in a ratio of eight to one. This significant labor time reduction resulted not only in more efficient and predictable searches, but also increased the moral of the workers. In reality, the number of temporarily missing components was almost eradicated. This facilitated the continuous retrieval and installation of these components. As a consequence, the erection productivity was significantly increased.

These savings were demonstrated to potentially result in significant project benefits if the automated tracking methodology had been widely applied. Important cost savings and schedule reductions could have been attained to justify the implementation of these tracking technologies. These tangible benefits are critical to drive the implementation of materials tracking technologies on construction job sites.

Future efforts should address the implementation of these tracking technologies from manufacturing to installation. Indeed, they could record and store component information regarding design, procurement, fabrication, delivery, transportation, receiving, installation, and maintenance. The instant visibility of construction elements through their life-cycle could significantly improve the efficiency of the capital investment industry. Such a thorough-going advancement stands to become another driving force for opening the doors to these and other technology solutions within the industry.

\section{Acknowledgements}

The authors would like to acknowledge the Construction Industry Institute and FIATECH for their financial support. They would also like to recognize the support received from Bechtel and Identec.

\section{References}

[1] Caldas, C. H., Grau, D., and Haas, C. T. (2006). "Using Global Positioning System to Improve Materials-Locating Processes on Industrial Projects.” Journal of Construction Engineering and Management, 132(7), 741-749.

[2] CII (1999). "Procurement and Materials Management: A Guide to Effective Project Execution." The Construction Industry Institute, Implementation Resource 7-3.

[3] Goodrum, P.M., McLaren, M.A., and Durfee, A. (2006). "The Application of Active Radio Frequency Identification Technology for Tool Tracking on Construction Job Sites." Automation in Construction, 15(3), 292-302.

[4] Grau Torrent, D. (2008). "Development of a Methodology for Automating the Localization and Identification of Engineered Components and Assessment of its Impact on Construction Craft Productivity." Ph.D. Thesis, The University of Texas at Austin, Austin, Texas.

[5] Grau, D., and Caldas, C.H., (2009). "Methodology for Automating the Identification and Localization of Construction Components on Industrial Projects.” Journal of Computing in Civil Engineering, 23 (1), 3-13.

[6] Navon, R., and Berkovich, O. (2006). "An Automated Model for Materials Management and Control." Construction Management and Economics, 24(6), 635-646.

[7] Rojas, E. M., and Aramvareekul, P. (2003). "Labor Productivity Drivers and Opportunities in The Construction Industry.” Journal of Management in Engineering, 19(2), 78-82.

[8] Sacks, R., Navon, R., and Goldschmidt, E., (2003). "Building Project Model Support for Automated Labor Monitoring." Journal of Computing in Civil Engineering, 17 (1), 19-27.

[9] Song, J., Haas, C.T., and Caldas, C.H. (2006). "Tracking the Location of Materials on Construction Job Sites.” Journal of Construction Engineering and Management, 132(9), 911-918.

[10] Vorster, M. C., and Lucko, G. (2002). “Construction Technology Needs Assessment Update.” The Construction Industry Institute, Research Report 173-11. 